\title{
A Global Supply Network Design Model: A Resilient Management Approach
}

\author{
Kanchan Das \\ College of Engineering and Technology, \\ East Carolina University, NC 27858, USA. \\ Corresponding author: dask@ecu.edu \\ Adarsh Annand \\ Department of Operational Research, \\ University of Delhi, Delhi, India. \\ Mangey Ram \\ Department of Mathematics, Computer Science and Engineering, \\ Graphic Era Deemed to be University, Dehradun, Uttarakhand, India.
}

(Received October 29, 2020; Accepted January 15, 2021)

\begin{abstract}
We propose a design model for creating a resilient supply network applicable for local and global markets. It addresses the ineffectiveness and failure of existing supply network that resulted current economic, food and hospital supply crisis during this ongoing COVID 19 Pandemic situation. The research includes resilience creation approach for the known previously experienced as well as unknown and unforeseen disruption situations. This research considers resilience management-based steps and methods covered in the literature to building abilities of supply networks for absorption, adaptation and recovery for containing disruptions that have severe negative effect on supply chain operations and society. The research studies the options for including SC intermediaries to take the role of supply agent or supply contractors (SCON) to manage supply of items when traditional/classical supply networks known to us were almost inoperative or ineffective to fulfill buyer requirements during this COVID 19 like pandemic situations. A numerical example is solved for illustrating applicability of the model.
\end{abstract}

Keywords: Supply network, Resilience creation, Design model; Resilience management approach, Absorption, Adaptation, Recovery.

\section{Introduction}

COVID 19 created economic crisis and disrupted total social ecosystems that we have been experiencing every day. It also challenged supply chain (SC) resilience creation approaches of the SC literature (Ivanov and Dolgui, 2020; Ivanov et al., 2020). It clearly shows lack of resilience in SCs and the disruptions impacts in global scale (Golan et al., 2020). Supply system disruptions for hospital supply to day-to-day useable items (Toilet paper shortage, 2020) establishes that our approach should examine the supply network and their intertwined structure, not individual SCs and the set of suppliers dealt by them. Since supply networks are intertwined and complex (Braziotis et al., 2013; Ivanov and Dolgui, 2020), examination of supply networks will provide survival options by identifying better performers or still operating suppliers. Selection of such suppliers may provide options for supply system restoration and continuity. Since supply network disruptions experienced by SCs in this COVID 19 Pandemic are unprecedented. It is also apparent that risk management-based approach does not seem to address containment options effectively (Linkov et al., 2017). This is because such approach is probability based. While assumptions and 
International Journal of Mathematical, Engineering and Management Sciences

Vol. 6, No. 2, 660-676, 2021

https://doi.org/10.33889/IJMEMS.2021.6.2.041

scenario-based steps may provide options to proceed with risk management-based approach, this research follows resilience management approach by including absorptions, adaptation and recovery strategy considering unforeseen and uncertain disruptions and disruption impacts.

Extent of COVID 19 pandemic disruptions is enormous everyway that may not be contained until regional and global coordination is planned (Kimura et al., 2020). This is such because supply networks are mostly global. Such networks are always inter-country, inter regional and global in nature. For a robust approach such regional and inter regional cooperation may provide containment options by finding less disrupted and not disrupted organizations in some safer locations. Such regional cooperation supports early detection and initiation of steps to flatten the effect of any disease outbreaks pandemic curve which will also ease out demand side panic for overstocking. Such early mitigation policies are also supported by the study of World Bank (2020). It is also important to note that such regional and inter-regional policy coordination and the stability of global value chain will be valuable in the post-pandemic recovery for the businesses in the regions. Such coordination has been remaining broken down and may not be obtained soon. But since this research is not time bound, we design our supply network applicable to global and interregional supply network, when needed and applicable.

SC resilience and sustainability may be used in the same sense (Fiksel et al., 2014; Marchese et al., 2018) when we apply these terms for business continuity and persistence of the system over time. SC intermediaries may be used to facilitate overcoming failure of supply system sustainability and resilience (Cole and Aitken, 2020; Vedel and Ellegaard, 2013). Such intermediaries are often a part of global supplier network. By SC intermediaries Cole and Aitken (2020) considered distinct organizational form that occupies a position in global sourcing, may be a supply contractor and may sometimes become a supplier organization for supplying finished goods. In the Pandemic situations when markets have been operating only in a limited scale for online transactions, and all production organizations have not been operating due to non-availability of required employees. As such supply management systems are in non-operative conditions. In this Pandemic disruption situation such options of involving SC Intermediaries may be considered, especially when all other options are closed or not seemed working.

In the case where supply management system is still operating with limited capacity (for example e-markets, medical supply chains, pharmaceutical industries) by facing the pandemic situation crisis that should also be studied. Based on the findings and recommendations in Matapoulos et al. (2019) perceived organizational justice in buyer supplier relationships for risk sharing, and development of stronger relationships and commitment contributes in financial and operational performances in the crisis situation. Development of such risk sharing, and development of stronger relationships may be considered to face future Pandemic situations. In addition to empirical research findings, the approach proved successful with the outcomes they obtained from their analysis of grocery retailing network during the Greek financial crisis, which further exemplifies the usefulness of the approach.

In this research we plan to design resilient supply network in place of traditional supply system for an individual SC for containing unforeseen and unprecedented business and SC disruptions taking resilient management-based approach. We shall include above two potential resilience improvement options in our designs as much as possible. 
International Journal of Mathematical, Engineering and Management Sciences

Vol. 6, No. 2, 660-676, 2021

https://doi.org/10.33889/IJMEMS.2021.6.2.041

In addition, information visibility has been given importance in the recent study of Li et al. (2017) and past literature (Basole and Bellamy, 2014; Craighead et al., 2007). All these researches emphasized importance of supply visibility in terms of access to disruption information for failure mitigation taking risk management-based approaches. From the resilience management perspectives such visibility could provide adaptation and quick recovery options. In addition, such visibility could remove demand shock out of panic by the consumers by communicating through social media and taking advantages of already established IBM's IoT based higher level technology (Sanders, 2014).

Based on above discussions and information this research introduces a noble supply network design model that will be able to handle limited supply orders of a set of SCs considering them as customers. Since this research seeks to plan a resilient supply network it will include flexibilities, decentralizations and inventory creation at strategic locations in the perspectives of the supply networks applicable for intertwined global and local situations. The research is presented in the following structures: Section 2 includes relevant literatures and section 3 includes Research Methodology in terms of Mathematical Modeling based approach and section 4 includes a numerical example and Section 5 discusses and concludes.

\section{Study of Relevant Literature}

Literature on SC resilience is quite rich. But only a limited number of researches are available that cover SC disruptions and relevant resilience considerations considering disruptions and changes created by COVID 19 situations. Since number of articles are limited, we shall study literature under the streams of 1 . supply management disruptions and resilience; and 2. Supply network management disruptions and resilience.

\subsection{Supply Management Disruptions and Resilience}

Taking the advantage of globalization SCs go for multitier supplier for cost and quality related advantages. Bimpikis et al. (2019) followed a modeling-based approach where they plan production in their multitier SC management system after observing realized output by suppliers and by that they optimize cost. Planning of production based on confirmed supply items availability is equivalent to spot buying. Such approach may not be considered suitable to build resilience in COVID19 like Pandemic situations.

Implications of COVID 19 disruptions on Food supply chains (Hobbs, 2020) have not been much different from other products considering initial demand side peaks and shocks out of panics. Such demand shocks with the time became lower demand for prepared and packaged food when people were consuming home-made food only. Supply side shocks in food supply chain continued mainly because of labor shortages and transportation disruptions. Hobbs (2020) discussed on Canadian situation including the issue of traffic thickening at the USA-Canadian Border during this COVID 19 pandemic. Hobbs (2020) also studied longer lasting effects on the food supply chains including on-line grocery delivery sector and whether that sector will influence local food supply chains. On the resilience creation the author provided insights on collaborative supply chain relationships with long-term partnerships with suppliers that help reduce transaction costs, share risks, could provide access to complementary resources and expertise, and enhance productivity. The author considered buyer supplier relationship following Matopoulos et al. (2019)'s approach for risk sharing, and development of stronger relationships and commitment within buyer-supplier relationships. 
International Journal of Mathematical, Engineering and Management Sciences

Vol. 6, No. 2, 660-676, 2021

https://doi.org/10.33889/IJMEMS.2021.6.2.041

Rezapour et al. (2017) studied an automobile supply chain disruption case study for the supply system disruptions. Based on their detailed analysis they planned three policies that include: keeping emergency stock at the retailer's level. Such stock keeping is in effect reserving back-up capacity at the supplier's level, and multiple sourcing for containment of disruptions. Such steps seem to have some effectiveness even in the COVID 19 disruptions, when one does not run production and not need supply by suppliers at lower tiers. But for taking advantage of stock at the retailer's level and making the disruption containment steps to work, transportation arrangement should be organized.

Purchasing and supply management (PSM) plays a key role for supply management performance and overall supply chain performance, as reinforced in a recent study by Pereira et al. (2020). PSM has been responsible for pursuing proactive and reactive measures for ensuring procurement management performance, thus contributing to resilience. For such measures PSM had the authority over resources in addition to external and internal relations. From this perspective they had the ability to take reactive measure to procure from supply chain intermediaries as proposed by (Cole and Aitken, 2020) to tackle the traditional supply management failure cases considered in our research. Keeping backup supplier improves SC resilience under uncertain demand and supply disruption potential. Chakraborty et al. (2020) studied effect of keeping backup supplier under uncertain demand. Their finding using a game theoretic and price strategy-based approach showed improvement of supply management resilience through the backup supplier. But with COVID 19 situations such backup supplier did not work when suppliers' organizations stopped their operations. In some cases, operations of the supply organizations failed because of transportation failures. So, options were multiple layers of backups with alternative transportations. The study of Tsai (2016) considered optimum layers of backups and recommended a dynamic approach for including such layers of backups. Question may come, how to decide number of layers. Since the study is based on dynamic sourcing, multiple scenarios based, probabilistic approach will support such backups. In this case probabilities and scenarios may be developed dynamically, considering characteristics of disruptive situations to decide optimum backup layers.

\subsection{Supply Network Disruptions and Resilience}

Select research considered supply networks as the intertwined type or interconnected within the network. These organizations are conceptually considered to take buyer suppler roles (Ivanov et al., 2020; Ivanov \& Dolgui, 2020). Since they supply or interchange various goods (products, production inputs) and sometimes take the role of service provider for some services (mobility services), these interconnected SCs on their own can support each other to attain required resiliency. The authors considered developing resilience mechanisms to interchange supports (type of collaborative organizations) to each other based on visibility for requirements and capabilities of each other. Such resilience mechanisms seem to have the potential to support organizations in COVID 19 type pandemic situations by sharing and interchanging resources, capacities and capabilities. The study in Ivanov \& Dolgui (2020) has not provided more details beyond conceptualization.

Chibani et al. (2018) considered a set of supply chains and planned e-procurement using a modelbased approach for dynamic optimization of cost to handle uncertainty in procurement quantity and cost. The authors used genetic algorithm for solving the model. In each generation of solution, the algorithm changed the supplier mix. The overall problem and the solution for building resilience seem to work in the conceptual level only. 
Supply networks face random disruptions from natural calamity (e.g. earthquakes and tsunami) and targeted disruptions from military interventions/war, strike, employee noncooperation. For building resilience to such disruptions Shi et al. (2019) proposed an undirected graph theoretic model for transactions of products between suppliers (node) and enterprises (node) and from enterprises to retailers. They used a computer simulation to solve the model when such transactions are disrupted from random disruption events. The authors claimed their results in terms of LCC (number of subnetworks where each pair of nodes can be interconnected) better than the similar solutions in the literature. The result seems interesting but not much suitable to provide managerial insights for resilience when the approach is of conceptual in nature.

Azad and Hassini (2019) proposed recovery strategy for a supply network disruption situation. Their strategy considered dynamic pricing strategy, inventory keeping, transshipment and multiple sourcing for recovery from supply network disruptions. Each of these strategies proven to work very well in normal business situation but does not seem suitable for COVID 19 like situations.

Based on the above literature review; within the limited number of researches that addressed supply network disruptions to plan resiliency that had the potential to address disruptions caused by COVID 19 like Pandemic situations, resilience development approaches are still at the conceptual level. Individualized supply management resilience planning for containing disruptions are well planned but not suitable to handle disruptions that may arise from COVID 19 like pandemic situations. Only exception here is the Food SC study (Hobbs, 2020) which is well suited for addressing Pandemic situations. In our proposed model we considered supply network that may be formed by suppliers, supply contractor (SC intermediaries, as mentioned by Cole and Aitken, 2020). As such it can only be partially shut down which will be in operation quickly with some better situations. This is such, because SC intermediaries operate virtually in computer-based systems, sometimes as a broker ( $\mathrm{Li}$ and Choi, 2009) to establish relations between a supplier and buyer through computer-based information exchange. Such intermediaries may only need some rented warehouses to use as collection centers / distribution centers for creating planned stock of items as needed by the customers and distribute them to customers by taking support from 3PL logistics providers, which have been working in some form in this pandemic situations.

\section{Methodology}

Considering various parameters and number of entities to be considered, this research follows a mathematical modeling-based approach for designing resilient supply network. We have developed a bi-objective mixed integer programming model. This section includes Notations for defining model equations, Problem Statement and Formulation of Model.

\subsection{Notations}

$V$ : set of supply contractor (SCON) /Vendor $v \in V$ (right term for such SCON is the SC intermediaries).

$S$ : set of actual suppliers (ACS) $s \in S$ representing Pharmaceutical or any other manufacturing companies. Supplier may be an importer, a grower in certain occasions for some product.

I: set of items/ products supplied by SCONs (they maintain a product portfolio in their website that are supplied by them. The supply item $i \in I$ is the product based on product portfolio of the SCONs. The SCONs buy the items/product from actual supplier $s \in S$ (ACSs). 
International Journal of Mathematical, Engineering and Management Sciences

Vol. 6, No. 2, 660-676, 2021

https://doi.org/10.33889/IJMEMS.2021.6.2.041

$L$ : set of locations $l \in L$ from where actual supplier $s \in S$ originated. When applying for enlistment of a supplier $s$ with a supply contractor (SCON), they needed to declare their locations and detailed address.

$N$ : Set of distribution node (DSN used in the body of the paper) $n \in N ; n \in N^{k}$, here $N^{k}$ is the set of $D C s$ (Warehouses, collection center/Storage ) maintained by SCONs; destination can be $n \in N^{c}$ set of customer that order items to SCONs(vendor V). These are mentioned as destination node when warehouses/collection centers cannot operate due to some disruptions or some abnormal situation as COVID 19.

\subsection{Parameters}

$C S_{i s n}$ : cost of supplying item $i$ to DSN $n$ by suppliers.

$F S C_{i s}$ : fixed cost for ordering item $i$ to suppliers.

$F_{\text {FTn }}$ : Fixed cost for selecting 3PL logistics company $g$ for transporting items from supplier s to DSN $n$.

$C A P_{s i}:$.capacity of supplier s for supplying product $i$.

$P R_{r}$ : probability of scenario $r$. Let us consider $n$ scenario with probability value $1 / n$ for each scenario.

$T R C_{\text {isng }}$ : cost of transporting item $i$ from supplier $s$ to DSN $n$ through transportation contactor $\mathrm{g}$.

Let $A V y_{i s n g}$ : computed by dividing customer requirement zvicm / (number days for a period for which this order is applicable*number of suppliers).

\subsection{Decision Variables}

$S L T_{i s n}$ : average supply lead time of supplier $s$ to supply input items i to destination node (DC or DSNs ) $n$ based on scenario-based analysis for scenario $r$ to be included in the constraint (14) through $A V S L_{i s n r}$ ( average supply lead time) based on Google Map and assumed supplier location, average transportation time for scenario 1 , normal operating condition with average traffic density; scenario 2:transportation time in COVID 19 scenario with rare traffic but the driver cannot take coffee, food, and often closed rest area due to state emergency situation; scenario 3:emergency lifted, limited services to drivers including food, coffee and water available ; scenario 4: traffic condition and services to drivers are Okay, but traffic movement is sometimes disturbed due to , political processions/some form of natural calamity.

$\alpha u_{s l}=1$ if supplier $s$ is from location $l, 0$ otherwise.

$b u_{i s l}=1$ if supplier $s$ of location $l$ assigned supply order; 0 otherwise.

$x_{v i}$ : requirements of supply item $i$ by the $\operatorname{SCON} v$.

$z_{\text {vicm: }}$ : SCON $v$ is assigned a procurement orders for supplying item $i$ by a customer $c \in C$ (may be hospital, any other organization) from market (m).

$x z_{v s i}$ actual supplier (producing organization) $s$ is assigned supply order for item $i$ to be delivered to distribution node by the SCON $v$.

$n t r_{\text {sng: }} 1$, if for transporting item $i$ from supplier $s$ to DSN $n$ contractor $\mathrm{g}$ is selected; 0 otherwise.

$u_{i s:}$, if actual supplier $s$ is assigned product I, 0 otherwise. 
International Journal of Mathematical, Engineering and Management Sciences

Vol. 6, No. 2, 660-676, 2021

https://doi.org/10.33889/IJMEMS.2021.6.2.041

$w_{i n}: 1$, if $\mathrm{DSN} n$ is open or ready to receive load; 0 otherwise.

$y_{\text {isng: }}$ input $i$ from supplier s be to be transported to a DSN $n$ through 3PL logistics provider $g$.

$e y_{\text {isng }}$ : initial effective input supply to DSN $n$ which will create safety stock to support customers in emergency situations when supply from suppliers will be disrupted due to some uncertain conditions.

$s w_{n p}: 1$, if DSN $n$ is selected by SCON network considering position criteria (nearness to market $m$ or customer zone, availability/nearness to transportation hub $h$, and non-risk proneness for natural calamity and disease outbreak. Considering a score-based analysis. For an example: out of preselected locations ( 1 to 5), location 1 gets 8 (in 1 to 10 scale) for nearness to market, score 3 for transportation hub, and 9 for non-risk prone location: making total score 20, in a similar analysis location 2 gets 18 and similarly score for all locations will be considered to select a location for DSN $n$.

$d y_{\text {incmg: }}$ : distribution of supply item $i$ from DSN $n$ to customer $c$ of market $m$ through transportation contractor $g$ to fulfill market requirement.

$\alpha l_{n c m}: 1$, if DSN $n$ is allocated to supply customer $c$ in market $m, 0$ otherwise.

$\alpha l_{n c m}: 1$, if DSN $n$ is allocated to supply customer $c$ in market $\mathrm{m}, 0$ otherwise.

$\beta_{i s n}=1$, if supplier s is assigned to supply comparatively non-risk prone DSN $n \in N^{S F}, 0$ otherwise.

$\tau_{i s n}: 1$, if supplier $s$ is assigned to supply DSN $n, 0$ otherwise.

\subsection{Problem Statement}

We assume a supply network formed by a set of supply contractor (SCON) $V$ from which a set of items(products) $i$ are procured by a set of customers (customer organization) $C$. The supply contactors (SCONs) $V(v \in V)$ are globally located with different virtual and website addresses in different countries and may be reached by any company in the USA or from any other country. SCON $v$ uses set of different transportation modes through transportation contractor (3PL SP service provider) $g$ for transporting item (product) $i$ to customer $c$. Let $z_{\text {vicm }}$ be the item $i \in I$ procured by the customer $c$ of market $m$ from SCON $v$. The SCON $v$ organizes and procures supply items $i$ needed by customer $c$ of market $m$ through a set of actual supplier $S$. The SCON $v$ assigns $x z_{v s i c}$ : supply order to actual supplier (ACS) $s$ for delivery of item $i$ to a set of distribution center /node (DSN) $N^{k}\left(n \in N^{k}\right)$. The DSNs are combination of warehouses and cold storages used as distribution nodes (DSNs, DCs) for stocking items by the SCON. The SCONs maintain the stock and keep them ready to be opened when needed for complying with delivery schedule of customers. Such stocks also provide distribution flexibility and resilience to transportation and other failures on the inbound supply of items from suppliers to DSNs and ensures distribution of items to customer when some supply base become disconnected due to some disruptions or COVID 19 like problems. We assume ACSs are from a set of locations $L^{s}\left(l \in L^{s}\right)$. Location for each of these supplies are known based on their enlistment with the SCON $v$. SCONs maintain supply portfolio with all details for suppliers and supply locations. Based on the locations of ACSs and customers, SCON assign dedicated ACSs to some valuable and big customers in some occasions when DSNs are disrupted. SCONs plan supplier assignment to supply to DSNs ensuring supplier flexibility (more than one supplier assigned per supply item); supplier location flexibility (assigning suppliers from more than one location for the crucial items of a customer based on information from customer); assigning at least 
International Journal of Mathematical, Engineering and Management Sciences

Vol. 6, No. 2, 660-676, 2021

https://doi.org/10.33889/IJMEMS.2021.6.2.041

one supplier for a DSN (distribution node) located in safe or non-risk prone location for each crucial item.

The overall objective of the model is to make the supply networks resilient to disruptions and optimization of overall supply cost to customers. Based on the experience of SCON $v$ about supply situation, SCON $v$ work with supplier $s$ (ACS) to organize transportation of the supply items $I$ through 3PL SP (transportation contractor), with which SCON has the contractual arrangement). SCON informs transportation cost per unit of supply items through 3PL SP to suppliers to support them in transporting items to DSN. Such support through 3PL SP (service provider) will eliminate not getting transports/trucks or any other mode of transportation by $S$ (ACS) during any abnormal situation (calamity, disease outbreak). Let $y_{\text {isng }}$ :input $i \in I$ to be transported to assigned/selected DSN $n$ through the 3PL SP $g$. Objective of the Model is to maximize Resiliency and minimize Total Cost for supply network operation as defined in Objective functions 1 and 2 to be followed.

\subsection{Formulation of the Model}

Constraint (1) estimates overall requirement of a supply item for a SCON's customers from all markets.

$$
x_{v i}=\sum_{c \in C} \sum_{m \in M} z_{v i c m} \quad \forall v, i
$$

Equation (2) balances supply order received by a SCON from the customers of different markets with procurement order placed by the SCON.

$$
\sum_{s \in S} x z_{v i s}=\sum_{m \in M} \sum_{c \in C} z_{v i c m} \quad \forall v, i
$$

Constraint (3) limits assignment of product /item to a supplier based on its capacity. Constraint (4) assigns more than one supplier for supplying a product. Constraint (5) verified and validated 0/1 variable $b u_{i s l}$. Based on constraint (6), each input item is assigned to suppliers from more than one location. Equation (7) balances quantity of items transported by the SCONs to the quantity ordered to them. Constraint (8) ensures transportation to DSN that is open for receiving transported load. Equation (9) computes average per day inventory as supplied by a supplier considering $\mathrm{y}_{\text {isng }}$ to be the supply for one month with 20 operating days.

$$
\begin{array}{ll}
\sum_{v \in V} x z_{v i s} \leq u_{i s} C A P_{i s} & \forall i, s \\
\sum_{s \in S} u_{i s} \geq 1 & \forall i \\
a u_{s l} b u_{i s l} \leq u_{i s} & \forall i \\
\sum_{s \in S} \sum_{l \in L} b u_{i s l} \geq 1 & \forall i \\
\sum_{n \in N} \sum_{g \in G} y_{i s n g}=\sum_{v \in V} x z_{v i s} & \forall i, s
\end{array}
$$


International Journal of Mathematical, Engineering and Management Sciences

Vol. 6, No. 2, 660-676, 2021

https://doi.org/10.33889/IJMEMS.2021.6.2.041

$$
\begin{array}{ll}
\sum_{g \in G} \sum_{s \in S} y_{i s n g} \leq w_{i n} M & \forall i, n \\
A V y_{\text {isng }}=\sum_{s \in S} y_{\text {isng }} /\left(20 * \sum s\right) & \forall i, n, g
\end{array}
$$

Constraint (10) ensures allocation of more than one DSN (distribution node) for each supply item i. Constraint (11) plans to allocate supply items to the DSN based on their pre-decided locations/positions. Considering risk proneness as defined in the notations. Constraint (12) balances supply item to DSN with the distributed product from the DSN to customer in the market. Constraint (13) balances distribution of product to customer at the markets with the order quantity committed by SCON.

Constraint (14) allocates DSN to customer based on markets. Constraint (15) allocates more than one DSN to supply a customer of a market. Equation (16) estimated supply lead time based on Average lead times taking scenario-based analysis. Since there is no supply lead time data to estimate standard deviation for a situation like COVID 19. Equation (17) computes effective supply quantity to be sent to DSN by including safety stock as computed in the equation and original supply quantity $y_{i s n g .}$. We plan to maintain safety stock for the entire estimated supply lead time as computed in the equation (17). We assume that it will be a onetime stock creation. Constraint (18) assigns 3PL logistics transportation company for supporting suppliers to send effective supply item quantity to DSN

$$
\begin{array}{lc}
\sum_{n \in N} w_{i n} \geq 1 & \forall i, n \\
w_{i n} \leq s w_{n p} & \forall i, n, p \\
\sum_{s \in S} y_{i s n g}=\sum_{c \in C} \sum_{m \in M} d y_{\text {incmg }} & \forall i, n, g \\
\sum_{n \in N} \sum_{g \in G} d y_{\text {incmg }}=z v_{i c m} & \forall i, c, m \\
\sum_{i \in I} \sum_{g \in G} d y_{\text {incmg }} \leq a l_{n c m} M & \forall n, c, m \\
\sum_{n \in N} a l_{n c m} \geq 1 & \forall c, m \\
S L T_{i s n}=\sum_{r \in R} A V S L_{i s n r} P R_{r} & \forall i, s, n \\
e y_{i s n g}=y_{i s n g}+\sum_{l \in L} S L T_{i s n} A V y_{i s n g} & \forall i, s, n, g \\
\sum_{i \in I} e y_{i s n g} \leq n t r_{g s n} M &
\end{array}
$$


Constraint (19) allocates DSN to a supplier for ensuring its replenishment. Constraint (20) assigns more than one supplier for replenishing a DSN. Such assignment improves supply resiliency to a DSN through increase in supply flexibility. Constraint (21) ensures assignment of supplier to a DSN is effective when the DSN is in operation. Constraint (22) ensures assignment of at least one supplier to a DSN which is located in a safer zone. Constraint (23) ensures that safer location DSN is a part of DSNs operated by SCON. Constraints (24) and (25) work in a combined way and decides extra quantity of supply items (Inventory) to be procured from partner suppliers to compensate the shortages between the quantity of items ordered by SCONS to suppliers to fulfill market requirements and the quantity of items supplied by the supplier to DSNs. Extra inventory to be procured will be triggered by the $0 / 1$ auxiliary variable $a u x_{s n}$. These two equations in effect created resiliency improvement provisions for obtaining the extra inventory from partner suppliers if needed. The extra inventory or improvement options has the basis in constraint (4) that included supplier flexibility to have more than one supplier for each item.

$$
\begin{array}{lc}
\sum_{g \in G} y_{i s n g} \leq \tau_{i s n} M & \forall s, n, g \\
\sum_{s \in S} \tau_{i s n} \geq 1 & \forall i, n \\
\tau_{i s n} \leq w_{i n} & \forall i, s, n \\
\sum_{s \in S} \beta_{i s n} \geq 1 & \forall n \in N^{S F} \\
\beta_{i s n} \leq \tau_{i s n} & \forall i, s, n \in N^{k} ; n \in N^{S F} \\
\sum_{i \in I} \sum_{g \in G}\left(y_{i s n g}+I A_{i s n g}\right)-\sum_{i \in I} \sum_{v \in V} \sum_{c \in C} \sum_{m \in M} z_{\text {vicm }} \leq M\left(1-a u x_{s n}\right) & \forall s, n \\
I A_{i s n g} \leq a u x_{s n} M & \forall s, n
\end{array}
$$

Objective Function 1: maximizes resilience $(R S)$ as defined in equation (26). RS is defined as a measure of coefficient of performance in equation (27) as the ratio of quantity of items procured and sent to DSNs which are to be distributed to customer in the markets to fulfill their requirements to the quantity of items SCON (supply contractor) committed to supply to customers by accepting orders.

Maximize Resilience $R S$

$$
R S=\frac{\sum_{i \in I} \sum_{s \in S} \sum_{n \in N} \sum_{g \in G}\left(y_{i s n g}+I A_{i s n g}\right)}{\sum_{v \in V} \sum_{i \in I} \sum_{c \in C} \sum_{m \in M} z_{v i c m}}
$$

Objective function 2 defined in equation (28) minimizes total supply network operation cost $T C$. $T C$ is defined in equation (29) in terms of its components: supply management cost (CSUP), cost for transporting supply items to DSN (CSTR) and costs for distributing product from DSN to customers $(C S D R)$.

Objective Function 2: minimize (TC) 
International Journal of Mathematical, Engineering and Management Sciences

Vol. 6, No. 2, 660-676, 2021

https://doi.org/10.33889/IJMEMS.2021.6.2.041

$T C=C S U P+C S D R+C S T R$

$C S U P=$ Supply management cost CSTR $=$ Cost of Transportation for supply items; $C S D R=$ Cost of distribution of product from DSN to customers at markets.

Supply management cost CSUP is defined in equation (30) by considering cost of supply items and fixed cost for assigning orders to suppliers. CSUP also includes cost of procuring extra inventory if needed and fixed cost for triggering such Improvement option/filling the gap for shortage of inventory by aux $_{s \mathrm{n}}$ becoming 1 . Equation (31) computes CSTR transportation cost from supplier location to DSN according to contractual rate of per product for such transportation and fixed cost for selecting 3PL Logistics company for transportation. Equation (32) computes distribution cost CSDR for supplying/distributing product from DSN to customer in each market plus fixed cost for allocating DSN to supply customer in market $m$. Constraint (33) imposes integrality.

$$
\begin{aligned}
& C S U P=\sum_{i \in I} \sum_{s \in S} \sum_{n \in N} \sum_{g \in G}\left(e y_{i s n g} C S_{i s n}+I A_{i s n g} * C S_{i s n}+F C_{X S W n} * X S W_{s n}\right)+\sum_{i \in I} \sum_{s \in S} F S C_{i s} u_{i s} \\
& C S T R=\sum_{i \in I}\left(\sum_{s \in S} \sum_{n \in N} \sum_{g \in G} e y_{i s n g} T R C_{i s n g}\right)+F T R_{\text {sng }} n t r_{\text {sng }} \\
& C S D R=\sum_{g \in G} \sum_{i \in I}\left(\sum_{n \in N} \sum_{c \in C} \sum_{m \in M} d y_{\text {incmg }} C D R_{i n c m}+F D R_{n c m} a l_{n c m}\right)
\end{aligned}
$$

Constraint (33) imposes integrality.

$u_{i s} \in\{0,1\}, \forall i, s ; b u_{i s l} \in\{0,1\} \forall i, s, l ; w_{i n} \in\{i, n\}, \forall i, n ; s w_{n p} \in\{0,1\}, \forall n, p ; a l_{n c m} \in\{0,1\}, \forall n, c, m$

\section{Numerical Example}

We assume a set of 5 supply contractors (SCONs) operate in 6 markets where they have customer organizations with demand for 12 products of their product portfolio based on their previous business in the markets. In this section we plan to cover model outcomes mainly. We include limited input information when such input information is important for explaining model outcomes. The SCONs are networked with several actual suppliers (ACSs) in USA, other countries and continents through their counterparts (SCONs) operating in those countries and continents. Considering shut down of air travel, export and import provisions in March-April-May of 2020 due to COVID 19 pandemic situations, the SCONs connected their 7 suppliers in USA for fulfilling customer orders they received for their 12 products. The SCONs identified 6 suitable DSNs (Distribution centers at an optimum location considering supply time from suppliers to DSNS and from there to 8 customers in 6 markets that ordered products to SCONs. Within the 6 DSNs one of them is in a comparatively safe location where effect of COVID 19 is lower over the period (AprilMay-June-July).The DSNs will be used for receiving items to be supplied by suppliers and distributing products from there to customers. The SCONs organized making the DSNs ready for operation (opening them for operation).

Table 1 presents typical product demand in Market 1 . To take an example for illustrations, Product 1 has demand from the customers 1 to 8 , respectively $\{54,45,61,63,56,59,56$ and 58$\}$. Demand for other product from these customers may be similarly explained. 
International Journal of Mathematical, Engineering and Management Sciences

Vol. 6, No. 2, 660-676, 2021

https://doi.org/10.33889/IJMEMS.2021.6.2.041

Table 1. Typical customer demand for products.

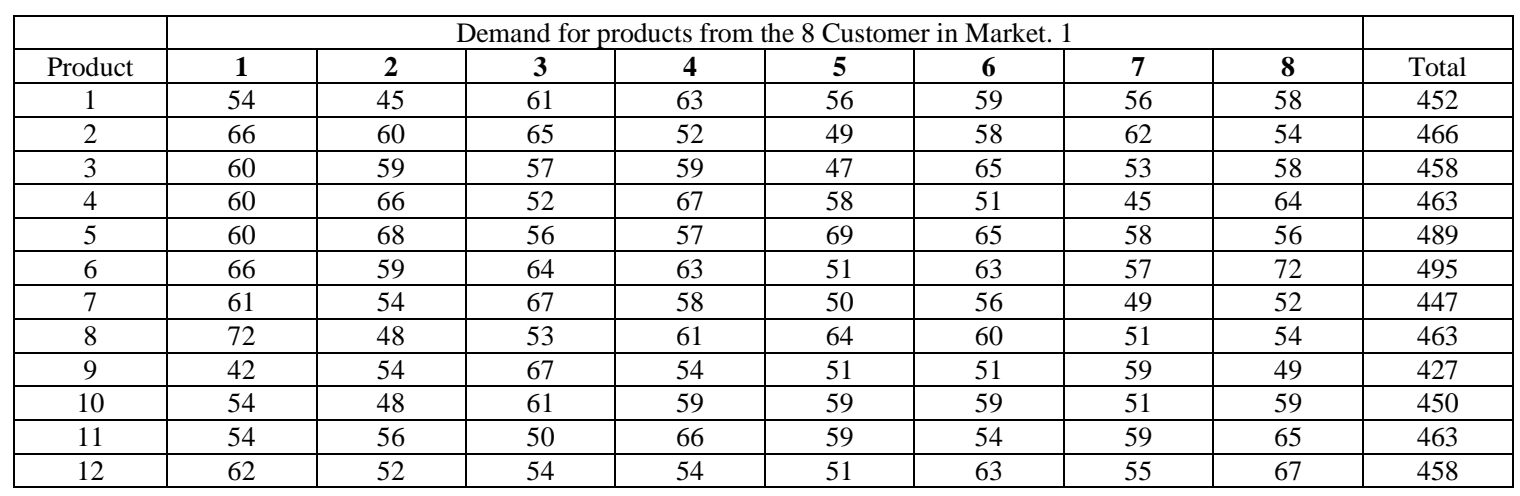

We solved the proposed model for the example numerical problem using commercial solver LINGO 18.0 in a standard PC Dell Latitude 5590 with Processor Intel Core (TM) i7 8650U CPU @ $1.90 \mathrm{GHz} 2.11 \mathrm{GHz}$ 32-bit operating system with Windows 10 Enterprise, Installed RAM 16 GB. The model solution for the example problem involved 21, 546 total variables, 1,249 integers and 5,930 constraints.

Table 2 presents typical model decision for assigning supply orders for 12 products to suppliers (1 to 7). Based on Table 2 each product is assigned to 2 to 3 suppliers. For an example product 1 assigned to suppliers 3,4 and 5 whereas product 3 is assigned to 2 suppliers 3 and 5 as may be observed in Table 2. Table 2 also presents model decision for allocation of DSNs for each product (please see the lower part of Table 2). As is apparent, the model solution provided importance to flexibility, thus to resiliency creation for supply and distribution management. Similar to assignment of suppliers to each product, the model allocated 3 to 4 DSNs to each product. The model allocated DSNs 1,5 and 6 for each with exceptions for product 7 and 11 . The model decided such allocation to be the optimum in terms distribution and transportations costs as well as distances.

Table 2. Assignment of supply orders to supplier and allocation of DSNs (distribution centers for each product.

\begin{tabular}{|c|c|c|c|c|c|c|c|c|c|c|c|c|c|}
\hline & \multicolumn{10}{|c|}{ Supply Flexibility } \\
\hline Product & 1 & 2 & 3 & 4 & 5 & 6 & 7 & 8 & 9 & 10 & 11 & 12 \\
\hline $\begin{array}{c}\text { Assigned } \\
\text { suppliers }\end{array}$ & $(3,4,5)$ & $(2,5,6)$ & $(3,5)$ & $(1,3)$ & $(1,7)$ & $(5,6)$ & $(5,6)$ & $(1,7)$ & $(1,2,5)$ & $(3,5)$ & $(5,6)$ & $(1,7)$ \\
\hline & 010 \\
\hline \multicolumn{10}{|c|}{ Distribution center flexibility, w $(i, n)$ assigning more than one DSN each product } \\
\hline Allocation of DSNs & $(1,5,6)$ & $(1,5,6)$ & $(1,5,6)$ & $(1,5,6)$ & $(1,5,6)$ & $(1,5,6)$ & $(1,4,5,6)$ & $(1,5,6)$ & $(1,5,6)$ & $(1,5,6)$ & $(1,4,5,6)$ & $(1,5,6)$ \\
\hline
\end{tabular}

Table 3 presents typical allocations of DSNs to customers in the markets for distributing product. For an example, Customer 1 in Markets 1,2,3 and 5 are supplied from DSN 6; in markets 4 and 6 it is supplied from DSN (1). In Market 4 it is supplied from DSN (5) also in addition to DSN (1). Based on Table 3, we may similarly illustrate for the customers 2 to 8 in different markets. 
International Journal of Mathematical, Engineering and Management Sciences

Vol. 6, No. 2, 660-676, 2021

https://doi.org/10.33889/IJMEMS.2021.6.2.041

Table 3. Model decisions on allocation DSN (Distribution centers) to typical customers in the markets.

\begin{tabular}{|c|c|c|c|c|c|c|}
\hline & \multicolumn{6}{|c|}{ Allocation of DSNs to the customers at markets. } \\
\hline Customers & 1 & 2 & 3 & 4 & 5 & 6 \\
\hline 1 & DSN (6) & DSN (6) & DSN (6) & DSN (1,5) & DSN (6) & DSN (1) \\
\hline 2 & DSN (6) & DSN (6) & DSN (6) & DSN (1) & DSN (6) & DSN (1) \\
\hline 3 & DSN (6) & DSN (6) & DSN (6) & DSN (1) & DSN (6) & DSN (1) \\
\hline 4 & DSN (6) & DSN (6) & DSN (6) & DSN (1) & DSN (6) & DSN (1,5) \\
\hline
\end{tabular}

We solved the model for the following typical scenarios to provide clear insights to supply chain Managers who may be interested to plan Resiliency creation for their unique businesses in COVID 19 like situation. The scenarios are also important for general readers.

Scenario 1: normal business condition, a business may expect $100 \%$ coefficient of performance considering planning of the business by including various resilience creation criteria (such as supply flexibility, DSN flexibility, and creating safety stock for making the business resilient. Scenarios 2 to 8: Due to COVID19 or similar other business disruption, we assumed supply scenarios for $95 \%$ to $65 \%$ or lower than $65 \%$ of items received out of the items ordered to them. Analysis in Table 5 is included to provide managerial insights about the impacts of such supply failure scenarios to business performance. The supply failure situations resulted resilience performance metrics presented in Table 4. Reasons for supply failures may be one or more of the following:

- COVID 19 like disease outbreaks created the situation that restricted supply organizations getting required manpower for producing the product.

- Suppliers could get only a limited amount of ingredients / raw materials from their suppliers.

- Due to a natural calamity the most part supplier's factory went under water and suppliers could only manage limited amount of product.

- Due to natural calamity suppliers could get only limited amount to inputs.

- Due to state emergency highway transportations were disrupted in several areas. As such Supplying of items to DSN was very challenging.

- There were political violence's that also restricted suppliers to supply items to DSN.

For each of the resilience performance metrics we also solved total supply network operations cost following Objective function 2 and the constraints in the last column.

Table 4 presents total supply network operation costs and its components for various models defined in the last column of Table 4. As may be observed in Table 4, as the resilience performance decreases, SC operation cost decreases, which may be considered obvious. Depiction resilience and SC operation cost decrement may also be observed in the Figure 1 trend lines for various SC costs. Which also seem obvious. This is because lower resilience performance value comes when supply of product is lower the requirement or lower than the ordered quantity of product to suppliers.

Trend lines in Figure 1 present trends for cost components for various SC operation scenarios. As discussed before resilience performance metric values decrease when supply quantity is lower than the product ordered. As supply quantity decreases compared to ordered quantity, due to which supply network resilience decreases and, total supply network operation cost as well as components 
International Journal of Mathematical, Engineering and Management Sciences

Vol. 6, No. 2, 660-676, 2021

https://doi.org/10.33889/IJMEMS.2021.6.2.041

of operation costs (CSUP, CSTR , CSDR) also decrease, which may also be observed in the trend lines for various resilience performance decrement cases.

Table 4: Summaries of model solution for various supply sceneries and their models.

\begin{tabular}{|c|c|c|c|c|c|c|c|}
\hline & RS & TC & CSUP & CSTR & CSDR & Scenarios & Model \\
\hline 1 & 1 & 295.35 & 127.257 & 64.95 & 103.14 & $\begin{array}{c}\text { Normal business } \\
\text { condition }\end{array}$ & minimize TC, s.t. Res $=1$ \\
\hline 2 & 0.95 & 288.57 & 122.018 & 62.078 & 104.469 & $\begin{array}{c}5 \% \text { supply disrupted by } \\
\text { COVID pandemic }\end{array}$ & $\begin{array}{c}\text { minimize TC, s.t. } S N R E S \geq \\
\text { 0.95 }\end{array}$ \\
\hline 3 & 0.9 & 284.57 & 124.17 & 62.6 & 97.8 & $\begin{array}{c}10 \% \text { disrupted by } \\
\text { COVID }\end{array}$ & $\begin{array}{c}\text { minimize TC, } \text { s.t. } S N R E S \geq \\
\text { 0.90 }\end{array}$ \\
\hline 4 & 0.85 & 279.04 & 115.18 & 61.19 & 102.67 & $\begin{array}{c}15 \% \text { disrupted by } \\
\text { COVID }\end{array}$ & $\begin{array}{c}\text { minimize TC, s.t. } S N R E S \geq \\
\text { 0.85 }\end{array}$ \\
\hline 5 & 0.8 & 270.58 & 114.68 & 52.77 & 103.13 & $\begin{array}{c}20 \% \text { disrupted by } \\
\text { COVID }\end{array}$ & $\begin{array}{c}\text { minimize TC, s.t. } S N R E S \geq \\
\text { 0.80 }\end{array}$ \\
\hline 6 & 0.75 & 262.84 & 110 & 54.47 & 98.37 & $\begin{array}{c}25 \% \text { disrupted by } \\
\text { COVID }\end{array}$ & $\begin{array}{c}\text { minimize TC, s.t. } S N R E S \geq \\
\text { 0.75 }\end{array}$ \\
\hline 7 & 0.7 & 248.88 & 101.55 & 48.7 & 98.52 & $\begin{array}{c}30 \% \text { disrupted by } \\
\text { COVID }\end{array}$ & $\begin{array}{c}\text { minimize TC, s.t. } S N R E S \geq \\
\text { 0.70 }\end{array}$ \\
\hline 8 & 0.65 & 238 & 91.54 & 43.72 & 103.14 & $\begin{array}{c}35 \% \text { disrupted by } \\
\text { COVID }\end{array}$ & $\begin{array}{c}\text { minimize TC, s.t. } S N R E S \geq \\
\text { 0.65 }\end{array}$ \\
\hline
\end{tabular}

RES: Supply Network Resilience, Objective 1 value; TC: Total Supply network operation cost for the scenario and for the defined model; CSUP: cost as defined in model equation (31); CSTR: cost is defined in equation (32); CSDR : cost as defined in model equation (33).

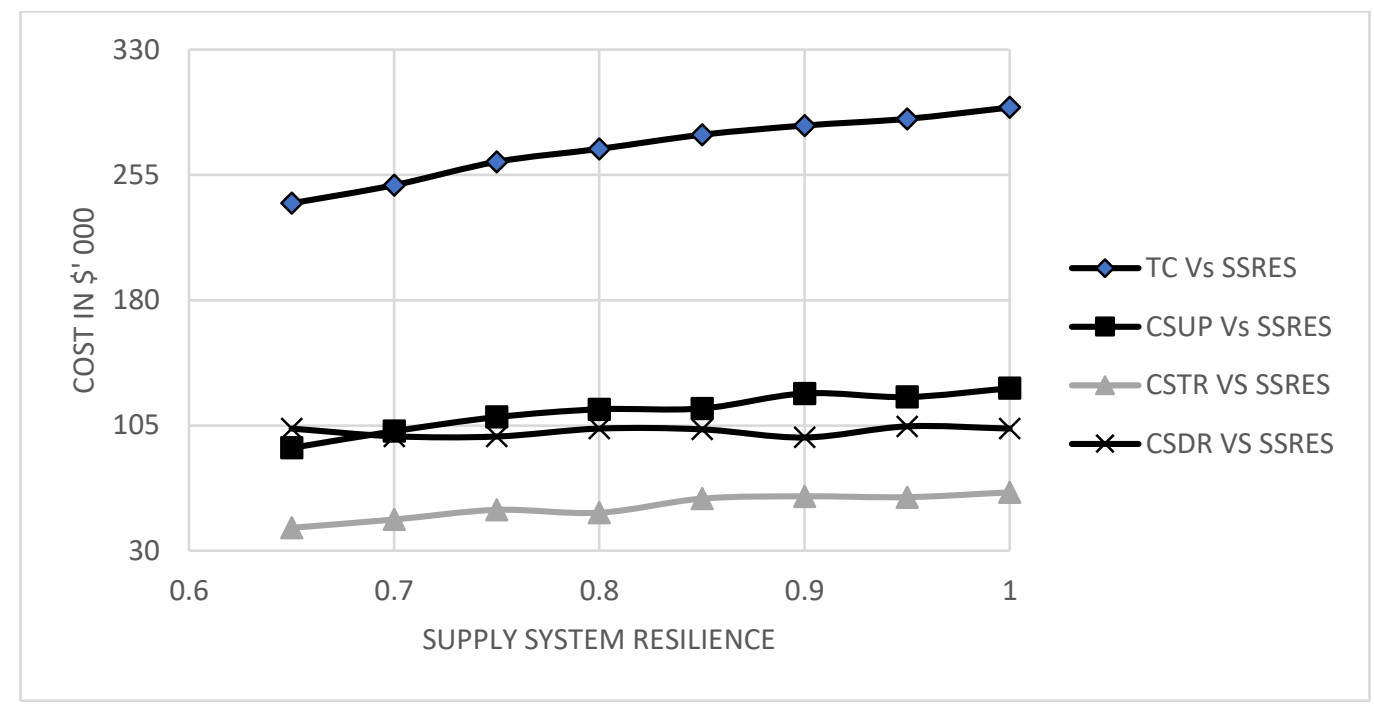

Figure 1. Trend line for various supply network costs at various scenarios.

\section{Discussions}

Based on the analysis of model findings as presented for numerical example solutions, it is apparent that in a pandemic situation where supply systems for a SCs become inoperative, SCs have the options to consider SC intermediaries for managing their procurement of supplies. As covered before such intermediaries like the SCONs (supply contactors or, supply agents) are small one to 
International Journal of Mathematical, Engineering and Management Sciences

Vol. 6, No. 2, 660-676, 2021

https://doi.org/10.33889/IJMEMS.2021.6.2.041

two-person organizations with computer-based network connections. They maintain network relationships with several similar organizations in USA and across entire globe. In the case example when businesses were unable to get supply in USA, these SCONS could get small supply sources. They (SCONS) supported these small actual suppliers with 3PL transportation contractors to transport the items ordered to them to supply to warehouses. From the warehouses the SCONS could supply the items ordered to them by their customers. These customers may be considered Companies who used to depend on their supply systems. But could manage their procurement of inputs through these SCONS through when traditional supply systems became inoperative. In addition, these SCONS went for multilayer flexibilities (please refer to Tables 2 and 3 for supply and distribution flexibilities to ensure procurement of items and their distribution to customers who entrusted them for their supplies in the pandemic situation when their traditional supply system failed. The scenario analysis includes resilience performance based on $\%$ supply items that could be procured in these pandemic situations considering various disruptions and disturbances occurred. Analysis of various scenarios presented above are for managerial insights considering the effect of disturbances and resilience performances.

\section{Conclusions}

The proposed research introduced a new and innovative alternative approach for fulfilling business requirement in a difficult business environment like COVID 19 Pandemic situations, by involving SC intermediaries (like supply contractors, supply agents, supply agency networks). The research includes resiliency creation options to address business requirements through resilience management-based approach for containing unforeseen and unanticipated business disruptions by creating multilayer flexibilities for making supply and distribution system resilient. The research also includes various practical scenario-based analysis to provide clear insights to SC managers for improving resilience and cost performances of their unique businesses for each of the such scenarios. The research has the scope of extending it by including classical supplier pools and SC intermediaries in a combined way. The research has the potential to go for future extension by considering more customers, suppliers and DSNs to make it suitable for global SC disruptions situations.

\section{Conflict of Interest}

The authors confirm that there is no conflict of interest to declare for this publication.

Acknowledgement

This research is supported by the authors and as such no one to acknowledge.

\section{References}

Azad, N., \& Hassini, E. (2019). Recovery strategies from major supply disruptions in single and multiple sourcing networks. European Journal of Operational Research, 275(2), 481-501.

Basole, R.C., \& Bellamy, M.A. (2014). Supply network structure, visibility, and risk diffusion: A computational approach. Decision Sciences, 45(4), 753-789.

Bimpikis, K., Candogan, O., \& Ehsani, S. (2019). Supply disruptions and optimal network structures. Management Science, 65(12), 5504-5517.

Braziotis, C., Bourlakis, M., Rogers, H., \& Tannock, J. (2013). Supply chains and supply networks: distinctions and overlaps. Supply Chain Management: An International Journal, 18(6), 644-652. DOI:10.1108/SCM-07-2012-0260. 
International Journal of Mathematical, Engineering and Management Sciences

Vol. 6, No. 2, 660-676, 2021

https://doi.org/10.33889/IJMEMS.2021.6.2.041

Chibani, A., Delorme, X., Dolgui, A., \& Pierreval, H. (2018). Dynamic optimization for highly agile supply chains in e-procurement context. International Journal of Production Research, 56(17), 5904-5929.

Cole, R., \& Aitken, J. (2020). The role of intermediaries in establishing a sustainable supply chain. Journal of Purchasing \& Supply Management, 26(2), 100533.

Fiksel, J., I. Goodman, I., \& Hecht, A. (2014). Resilience: navigating toward a sustainable future. Solutions. Solutions, Burlington, VT, 5(5), 38-47.

Golan, M.S., Jernagan, L.H., \& Linkov, I. (2020). Trends and applications of resilience analytics in supply chain modeling: systematic literature review in the context of the COVID-19 pandemic. Environment Systems and Decisions, 40, 222-243.

Hobbs, J.E. (2020). Food supply chains during the COVID-19 pandemic. Canadian Journal of Agricultural Economics/Revue Canadian d'agroeconomie, 68(2), 171-176. DOI: 10.1111/cjag.12237.

Ivanov, D., \& Dolgui, A. (2020). Viability of intertwined supply networks: extending the supply chain resilience angles towards survivability. A position paper motivated by COVID-19 outbreak. International Journal of Production Research, 58(10), 2904-2915.

Ivanov, D., Dolgui, A., Blackhurst, J., \& Choi, T.M. (2020). Special issue: viability of supply networks and ecosystems: lessons learned from COVID-19 outbreak, International Journal of Production Research, editorial.

Kimura, F., Thangavelu, S.M., Narjoko, D., \& Findlay, C. (2020). Pandemic (COVID-19) policy, regional cooperation and the emerging global production network. Asian Economic Journal, 34(1), 3-27.

Li, Y., Zobel, C.W., \& Russell, R.S. (2017). Value of supply disruption information and information accuracy. Journal of Purchasing and Supply Management, 23(3), 191-201.

Linkov, I., Trump, B.D., Fox-Lent, C. (2017). Resilience in the face of danger, ISE Magazine, 49(3), 32-37.

Marchese, D., Reynolds, E., Bates, M.E., Morgan, H., Clark, S.S., \& Linkov, I. (2018). Resilience and sustainability: Similarities and differences in environmental management applications. Science of the Total Environment, 613-614 (February) 1275-1283.

Matopoulos, A., Didonet, S., Tsanasidis, V., \& Fearne, A. (2019). The role of perceived justice in buyersupplier relationships in times of economic crisis. Journal of Purchasing and Supply Management, 25(4), 100554.

Pereira, C.R., da Silva, A.L., Tate, W.L., \& Christopher, M. (2020). Purchasing and supply management (PSM) contribution to supply side resilience. International Journal of Production Economics, 228 (October), 107740.

Rezapour, S., Farahani, R.Z., \& Pourakbar, M. (2017). Resilient supply chain network design under competition: A case study. European Journal of Operational Research, 259(3), 1017-1035.

Sanders, N.R. (2014). Big data driven supply chain management: A Framework for Implementing Analytics and Turning Information into Intelligence 1st ed. Pearson Education, Inc.

Shi, X.Q., Long, W., Li, Y.Y., Deng, D.S., Wei, Y.L., \& Liu, H.G. (2020). Research on supply network resilience considering random and targeted disruptions simultaneously. International Journal of Production Research, 58(21), 6670-6688. https://doi.org/10.1080/00207543.2019.1685697.

Toilet paper shortage (2020). https://marker.medium.com/what-everyones-getting-wrong-about-the-toiletpaper-shortage-c812e1358fe0

Tsai, W.C. (2016). A dynamic sourcing strategy considering supply disruption risks. International Journal of Production Research, 54(7), 2170-2184.

Vedel, M., \& Ellegaard, C. (2013). Supply risk management functions of sourcing intermediaries: An investigation of the clothing industry. Supply Chain Management: An International Journal, 08/2013, Volume 18, Issue 5, 509-522. 
International Journal of Mathematical, Engineering and Management Sciences

Vol. 6, No. 2, 660-676, 2021

https://doi.org/10.33889/IJMEMS.2021.6.2.041

World Bank (2020). World Bank East Asia and Pacific Economic Update, April 2020: East Asia and the Pacific in the time of COVID-19. Washington, DC: World Bank. [Online; cited April 2020]. Available from URL: https://www.worldbank.org/en/region/eap/publication/east-asia-pacific-economic-update. (c) 1 Original content of this work is copyright () International Journal of Mathematical, Engineering and Management Sciences. Uses
under the Creative Commons Attribution 4.0 International (CC BY 4.0) license at https://creativecommons.org/licenses/by/4.0/ 